\title{
Renal Function in Analgesic Nephropathy
}

\author{
T. W. STEELE,* M.A., B.M., M.R.C.P.; A. Z. GYÖRY,† M.B., M.R.A.C.P. \\ K. D. G. EDWARDS, $\ddagger$ M.D., F.R.A.C.P., F.A.A.C.B.
}

British Medical Fournal, 1969, 2, 213-216

\begin{abstract}
Cummary : Comprehensive one-day renal function tests $\checkmark$ in 20 patients with a history of analgesic abuse showed varying degrees of chronic renal failure in all. There was no evidence of a selective defect in proximal tubular function, while a defective concentrating mechanism, usually considered necessary for the diagnosis of analgesic-induced renal damage, could be demonstrated in only 16 patients. A urinary acidification defect associated with a concentrating defect was found in nine cases and was thought to reflect specific collecting duct dysfunction. Urinary ammonium excretion was reduced in 13 subjects, owing to a reduced number of functioning nephrons or inadequate acidification, or both. Low citrate excretion was frequently encountered, and this, as well as defective urinary acidification, may play some part in predisposing patients with analgesic nephropathy to intrarenal calcification and progressive renal failure.
\end{abstract}

\section{Introduction}

Since 1953, when a possible association between excessive analgesic consumption and renal disease was first suggested (Spühler and Zollinger, 1953), numerous accounts of the clinical and pathological aspects of analgesic nephropathy have appeared. Although the manner in which these compounds ultimately effect renal damage is controversial (Harrow, 1967 Burry, 1968 ; Kincaid-Smith et al., 1968), histological studies leave no doubt that the renal medulla bears the early brunt of the damage, and that cortical changes occur secondarily (Sanerkin, 1966 ; Kincaid-Smith, 1967). By comparison there have been few detailed studies of renal function in analgesic nephropathy. Nevertheless, through the years the broad pattern of functional abnormalities has been established (Hultengren, 1961 ; Bengtsson, 1962 ; Reynolds and Edmondson, 1963 ; Pearson, 1967). As might be anticipated from the evolution of pathological changes, medullary function appears to be affected consistently and early. The purpose of the present investigation was to elucidate further the renal functional abnormalities associated with analgesic abuse, by measuring a large number of factors concurrently by the method of Edwards et al. (1964). A preliminary report of the results of some of the cases presented has been published previously (Steele et al., 1968).

\section{Patients and Methods}

The system of one-day renal function tests used in this department has presented an opportunity to study a number of patients in whom a diagnosis of analgesic nephropathy seemed probable from a history of an abnormally high and prolonged consumption of analgesic mixtures. The great majority of

* Fellow in Cardiorenal Diseases.

† Renal Research Fellow (National Health and Medical Research Council). $¥$ Associate Director and Senior Specialist in Charge.

eith Kirkland Renal Unit, Medical Research Department, Kanematsu Memorial Institute, Sydney Hospital, Sydney, N.S.W., Australia. patients took proprietary analgesic powders (Bex) containing aspirin and phenacetin ( $42 \%$ each by weight) and caffeine citrate ( $16 \%$ by weight). Patients with obstructive uropathy, acute pyelonephritis, and diabetes mellitus have been excluded from this study.

Twenty patients, of whom only one was male, were investigated. Their ages ranged from 30 to 66 years, with an average of 49 years. Fifteen patients had the complete range of tests performed within six months of diagnosis, at a time when their renal function was judged to be stable. In the remaining five cases the interval between diagnosis and testing averaged two years, and in these the complete range of tests was not performed. Each of the 20 patients had a total consumption of mixed analgesics containing phenacetin in excess of $1.5 \mathrm{~kg}$. In 10 the consumption exceeded $7 \mathrm{~kg}$. and in five was between 4 and $7 \mathrm{~kg}$. (as phenacetin).

Twenty-two healthy volunteers with an average age of 29 years formed a control group. They were tested under the same conditions as the patients. As details of the scheme of one-day renal function tests and of the methods used have been reported previously (Edwards et al., 1964 ; Györy and Edwards, 1968 ; Györy et al., 1969), only a brief outline is given here.

(1) Glomerular filtration rate (G.F.R.) and proximal tubular function were determined by endogenous creatinine clearance and the percentage excretion at 15 minutes of an intravenous dose (corrected for surface area) of phenolsulphonphthalein (P.S.P.) respectively.

(2) Renal concentrating capacity was assessed after subcutaneous administration of vasopressin tannate in oil, urinary osmolality being measured in three specimens passed during the eight hours of the test.

(3) The ability of the kidney to respond to an acid load was tested by the short ammonium chloride test of Wrong and Davies (1959). Blood acid-base values were measured before and after the administration of the acid load.

(4) Citrate excretion was determined in the urine sample tested for minimum urinary $\mathrm{pH}$.

(5) Also measured were blood urea nitrogen, electrolytes, plasma proteins, alkaline phosphatase, and the clearances of urate and phosphate.

\section{Results}

In six patients serum oreatinine levels were between 1 and $1.5 \mathrm{mg} . / 100 \mathrm{ml}$., and in only two did the level exceed $6 \mathrm{mg}$./ $100 \mathrm{ml}$. Four patients had normal serum creatinine levels. Details of creatinine clearance, phenolsulphonphthalein excretion, maximum urinary osmolality after vasopressin (max. $\mathrm{U}_{\text {osm. }}$ ) and urine flow rate at the time of its attainment, and plasma osmolality $\left(\mathbf{P}_{\text {osm. }}\right.$ ) are shown in Table $\mathbf{I}$. Renal failure as judged by creatinine clearance was absent or slight in six, moderate in nine, and severe in five patients.

Phenolsulphonphthalein excretion at 15 minutes was consistently reduced in patients with impaired filtration rates. There was a highly significant correlation between phenolsulphonphthalein excretion and oreatinine clearance $(P<0.001$, 
$\mathbf{r}=0.9$ ), similar to that observed by Healy et al. (1964) in patients with generalized renal disease.

Impairment of urinary concentration, the most frequently recorded abnormality, was present in 19 of the 20 cases. Case 11 with normal urine concentration had consumed $2.4 \mathrm{~kg}$. of phenacetin over 11 years. The regression equation obtainedmaximum urinary osmolality $\left(\mathrm{mOsm} . / \mathrm{kg} . \mathrm{H}_{2} \mathrm{O}\right)=313+3.28 \times$ creatinine clearance ( $\mathrm{ml} . / \mathrm{min} . / 1.73$ sq. m.), coefficient of correlation $(r)=0.87$-is very similar to that obtained by Bengtsson (1962) for a large number of patients with renal papillary necrosis.

TABLE I

\begin{tabular}{|c|c|c|c|c|c|}
\hline \multirow{2}{*}{$\begin{array}{l}\text { Case } \\
\text { No. }\end{array}$} & \multirow{2}{*}{$\begin{array}{c}\text { Creatinine } \\
\text { Clearance } \\
\text { (ml./min./ } \\
1 \cdot 73 \text { sq.m.). } \\
\end{array}$} & \multirow{2}{*}{$\begin{array}{c}\text { P.S.P. } \\
\text { Excretion } \\
\text { (\% Dose) }\end{array}$} & Max. Uosm. & Posm. & \multirow{2}{*}{$\begin{array}{c}\text { Urine } \\
\text { Flow } \\
\text { (ml./min.) }\end{array}$} \\
\hline & & & \multicolumn{2}{|c|}{$\mathrm{mOsm} . / \mathrm{kg} . \mathrm{H}_{2} \mathrm{O}$} & \\
\hline $\begin{array}{r}1 \\
2 \\
3 \\
4 \\
5 \\
6 \\
7 \\
8 \\
9 \\
10 \\
11 \\
12 \\
13 \\
14 \\
15 \\
16 \\
17 \\
18 \\
19 \\
20 \\
\end{array}$ & $\begin{array}{r}37 \\
54 \\
87 \\
11 \\
98 \\
9 \\
60 \\
51 \\
123 \\
40 \\
151 \\
7 \\
12 \\
34 \\
102 \\
37 \\
57 \\
44 \\
44 \\
74\end{array}$ & $\begin{array}{r}14.3 \\
2.0 \\
21.7 \\
4.5 \\
23.9 \\
2.5 \\
-9.1 \\
9.1 \\
19.8 \\
5.7 \\
25.6 \\
0.8 \\
1.8 \\
5.8 \\
25.1 \\
\overline{9.9} \\
= \\
=\end{array}$ & $\begin{array}{l}518 \\
597 \\
512 \\
288 \\
686 \\
300 \\
499 \\
429 \\
525 \\
510 \\
895 \\
289 \\
438 \\
404 \\
720 \\
404 \\
543 \\
275 \\
534 \\
494 \\
\end{array}$ & $\begin{array}{l}278 \\
286 \\
276 \\
277 \\
280 \\
306 \\
-184 \\
274 \\
303 \\
281 \\
301 \\
300 \\
278 \\
291 \\
= \\
= \\
\end{array}$ & $\begin{array}{l}1.75 \\
0.74 \\
1.28 \\
0.89 \\
0.94 \\
1.82 \\
1.00 \\
1.24 \\
2.09 \\
1.11 \\
1.09 \\
0.56 \\
0.41 \\
0.75 \\
1.18 \\
1.10 \\
0.89 \\
0.90 \\
0.84 \\
0.90 \\
\end{array}$ \\
\hline $\begin{array}{c}\text { Mean } \pm \text { S.D. } \\
\text { Normal } \\
\text { mean } \pm \text { S.D. }\end{array}$ & $\begin{array}{r}55 \pm 41 \\
132 \pm 20\end{array}$ & $\begin{array}{l}11 \cdot 5 \pm 9 \cdot 3 \\
31 \cdot 8 \pm 6 \cdot 2\end{array}$ & $\begin{array}{l}493 \pm 155 \\
931 \pm 89\end{array}$ & $\begin{array}{l}287 \pm 11 \\
281 \pm 58\end{array}$ & $\begin{array}{l}1 \cdot 07 \pm 0 \cdot 41 \\
1 \cdot 14 \pm 0 \cdot 34\end{array}$ \\
\hline
\end{tabular}

Impairment of urinary concentration, however, does not necessarily indicate renal damage (Kleeman et al., 1960). Under the conditions of one-day renal function testing, solute load and urine flow rates do not reach sufficient levels to permit measurement of maximum "free water" reabsorption. Up to the point at which "free water" reabsorption $\left(\mathrm{T}^{\mathrm{c}} \mathrm{H}_{2} \mathrm{O}\right)$ becomes maximal there is an inverse linear relation between the logarithmic values of max. $\mathrm{U}_{\text {osm. }} / \mathrm{P}_{\text {osm. }}$ minus 1 and urine flow rate corrected for glomerular filtration rate (Györy et al., 1969). It is therefore possible to represent a normal range with $95 \%$ tolerance limits ${ }^{1}$ (Fig. 1). The results from 17 cases are shown in this figure. Three patients who did not show any response to vasopressin are not represented. Of the 17 represented four (Cases 1, 5, 11, and 15) fall within the normal range. Although plasma osmolality was not measured in six cases (Table I), it has been assumed to be $287 \mathrm{mOsm} . / \mathrm{kg} . \mathrm{H}_{2} \mathrm{O}$. The possible range of variation of plasma osmolality is small, and makes no appreciable difference to the maximum $\mathrm{u} / \mathrm{p}$ osmolality ratio in these cases.

Details of urinary acidification and of ammonium, titratable acid, and citrate excretion are given in Table II. Also shown are the blood base excess values at the time of collection of urine samples. Urine culture on the day of testing did not show the presence of infection by Proteus species in any of these cases. Ten had some degree of impairment of urinary acidification, but one (Case 15) had a normal response on repeat examination. Chronic hyperchloraemic acidosis was present in four of the nine patients with a definite defect in urinary acidification, and has subsequently developed in a further three of them. All these patients either had or have subsequently developed severe renal failure.

1 The regression equation, $\log _{10} \mathrm{Y}=0.4307-0.1108 \mathrm{X}$ where $\mathrm{Y}=\mathrm{TCH}_{2}$ $\mathrm{O} / \mathrm{V}$ or max. $\mathrm{U}_{\mathrm{osm} .} / \mathrm{P}_{\mathrm{osm}} \mathrm{O}-1$ and $\mathrm{X}=$ urine flow in ml. per minute per $100 \mathrm{ml}$. Glomerular filtration rate was derived by calculation of our own data and those of Zak et al. (1954), Boyarsky and Smith (1957), Raisz et al. (1959), and Baldwin et al. (1965). There was no significant difference between the regression equation derived from our data and those of the other authors.
Ammonium and titratable acid excretion were below the normal range in 13 cases. In relation to urinary $\mathrm{pH}$, however, only six had an ammonium excretion below the normal range. Although creatinine clearance was reduced in all these patients, marked reduction in ammonium excretion was by no means invariable at low filtration rates. That the low ammonium

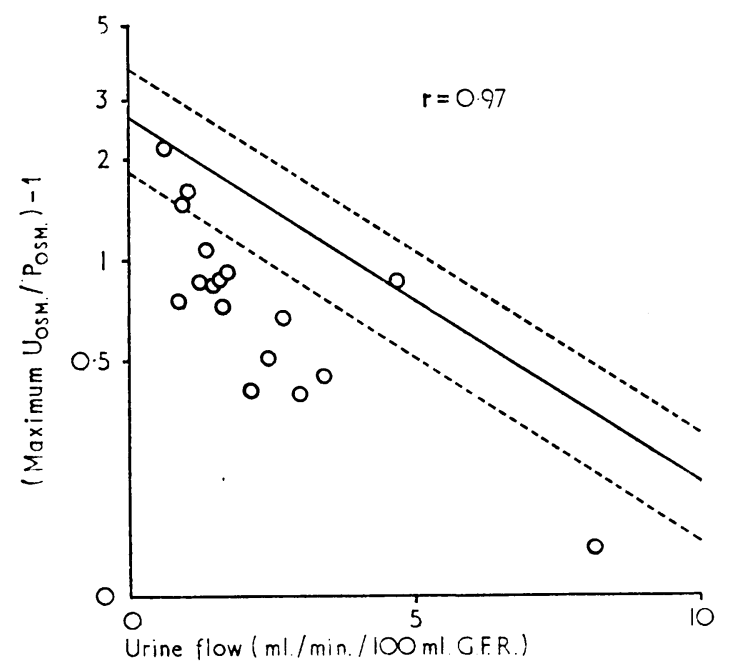

FIG. 1.-Variation of the logarithm of maximum urinary/ plasma osmolality ratio minus 1 and urine flow corrected for creatinine clearance. The solid and interrupted lines represent the regression line and 2 standard deviations for normal kidney controls $(n=51)$. Patients shown as open circles.

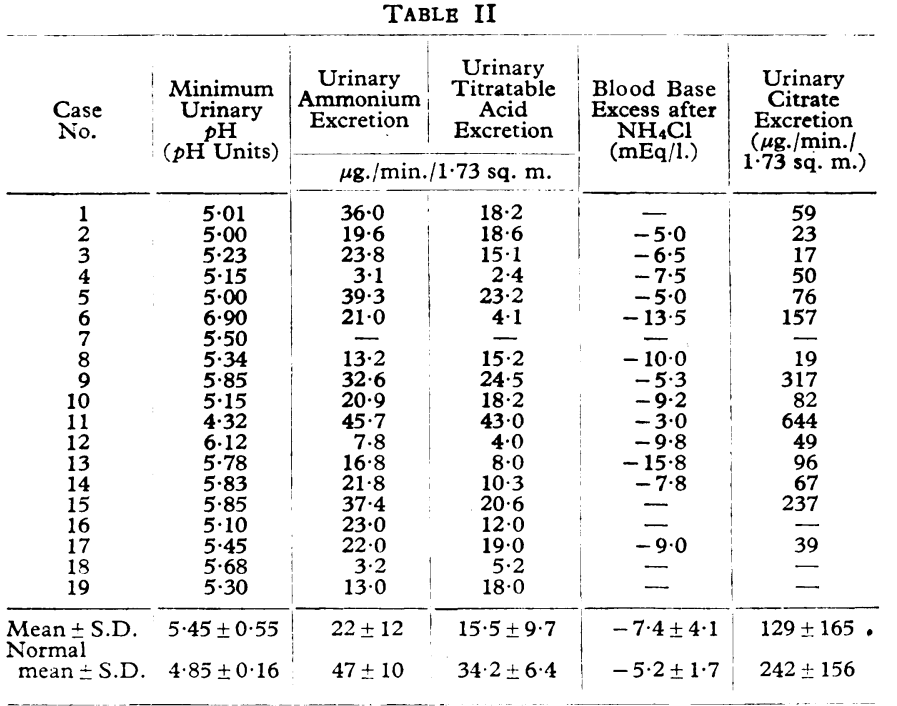

excretion can mainly be accounted for by the reduction in functional renal mass and/or defective acidification is shown in Fig. 2. When ammonium excretion was corrected for filtration rate, all had a normal or greater than normal excretion of ammonium relative to urinary $\mathrm{pH}$. The seven with a corrected excretion above the normal range had filtration rates below $40 \mathrm{ml}$. per minute, and presumably high urine flow rates in each of the remaining nephrons.

Urinary citrate excretion was found to be reduced in 9 of the 15 patients in whom it was measured. There was no correlation between citrate excretion and the degree of systemic acidosis induced by ammonium chloride. In two patients with chronic systemic acidosis citrate excretion was within the normal range ( $>80 \mu \mathrm{g} . / \mathrm{min} . / 1.73$ sq. m.).

Although joint symptoms were relatively uncommon, hyperuricaemia was a frequent finding in patients with advanced renal failure. The close correlation between serum uric acid and 
creatinine suggests that the hyperuricaemia is due to increased retention of uric acid in renal failure.

There was no biochemical evidence of hyperparathyroidism in any of the cases studied. In all cases plasma sodium and potassium levels were within normal limits, but an overall deficiency of body potassium has not been excluded.

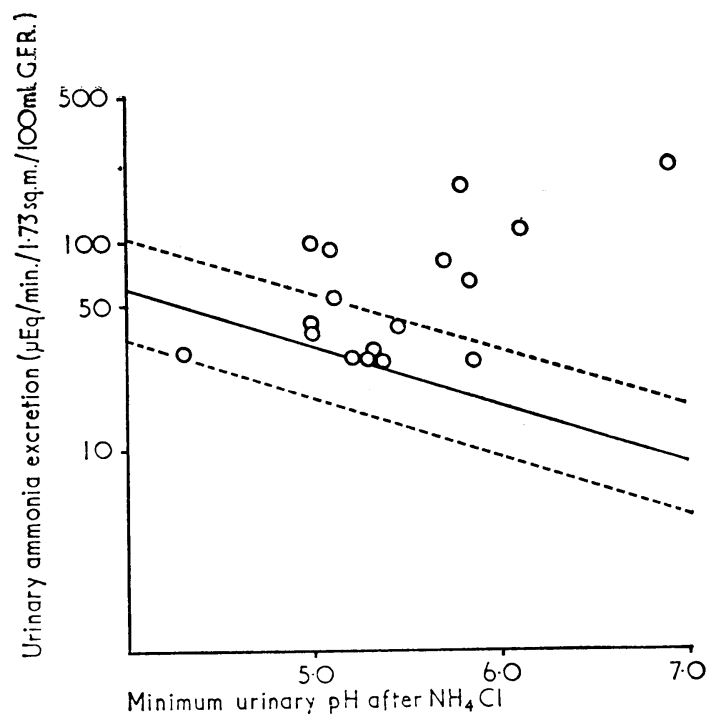

FIG. 2.-Variation of the logarithm of urinary ammonium excretion corrected for creatinine clearance and urinary $\mathrm{pH}$. The solid and interrupted lines represent the regression line and 2 standard deviations for 59 normal subjects. Symbols as in Fig. 1.

\section{Discussion}

It is apparent that the functional changes in analgesic nephropathy may take two major forms. On the one hand, there were those patients in whom normal urinary acidification was maintained even in the face of advanced renal failure, and, on the other, those with defective urinary acidification. Impairment of concentrating capacity, an invariable feature of analgesic nephropathy, was common to both groups. Hypocitraturia and varying degrees of renal failure were also found in both groups. The factors which determine the pattern of functional response elude detection.

Only one of the four cases with a filtration rate above $95 \mathrm{ml}$./ min. (Case 9) showed definite evidence of impaired concentrating capacity as defined by Fig. 2. The remaining three cases had no evidence of insufficiency of the countercurrent mechanism. Case 1, the fourth with no evidence of countercurrent insufficiency, is interesting in that the functional pattern she exhibited is in keeping with a predominantly glomerular lesion. In spite of her having consumed a total of $16 \mathrm{~kg}$. of phenacetin in the form of Bex powders, chronic glomerulonephritis remains the possible diagnosis, but has not yet been confirmed by renal biopsy.

Whether the unresponsiveness to vasopressin shown in Cases 6,12 , and 18 can be solely the result of very extensive medullary damage or is due to additional alteration in the permeability of the collecting ducts (Black, 1965) is not known with certainty. The coexistence of a defect in urinary acidification in these three cases suggests that damage to the collecting ducts may be important. Case 4, with a comparable filtration rate and normal urinary acidification, showed some increase in urine osmolality after vasopressin. Retesting of Cases 4 and 18 after one year has shown that both the acquired nephrogenic diabetes insipidus and the acidification defect persist in the latter, while Case 4 showed some improvement in concentrating ability. The acidification defect and acquired nephrogenic diabetes insipidus in analgesic nephropathy does not appear to have the reversible nature that is seen in chronic hydronephrosis (Berlyne, 1961).

A defect in urinary acidification was present in nine cases. Defective urinary acidification was invariably associated with a definite defect in urinary concentrating capacity, though, as mentioned above, the reverse was not true. In the early stages the concentrating defect may be due to damage of the ascending limb of the loop of Henle, with resultant inability to maintain medullary hyperosmolality. Such damage is found histologically (Burry, 1968). At a later stage necrosis of the papillae would further compromise the countercurrent mechanism. With the small numbers of patients in this study, it is not possible to say definitely whether collecting duct damage as shown by defective acidification additionally reduces concentrating capacity.

The results given in Fig. 2 show that the reduced excretion of ammonium is attributable to the decreased nephron population rather than to any specific inability to produce and excrete ammonia. What functioning nephrons remained in even severely damaged kidneys appeared to have a normal ability to excrete ammonium. The high corrected values of urinary ammonium excretion shown by some of the cases are to be expected in the situation of chronic systemic acidosis and/or high urine flow rates which were found in these cases. Both these factors are known to increase ammonium excretion in the normal kidney.

Urinary citrate excretion has not been extensively studied in analgesic nephropathy. Reduced citrate excretion may in part be responsible for the intrarenal calcification cornmonly encountered in analgesic nephropathy. The low citrate excretion in these patients does not correlate closely with the degree of acidosis attained with ammonium chloride loading. More surprising perhaps is the finding of normal citrate excretion in two patients with chronic acidosis, for it is known that citrate excretion is almost invariably reduced in patients with the inherited form of renal tubular acidosis. Preliminary investigations, however, suggest that patients with chronic systemic acidosis do not show the expected fall in citrate excretion after ammonium chloride. Their citrate excretion, therefore, while within the normal range under conditions of the test, appears to be very low if measured at random.

Although the prognosis in analgesic nephropathy does not appear to be as bad as in some other forms of renal disease, renal function may continue to deteriorate in spite of withdrawal of analgesics containing phenacetin. The poor prognosis of those with moderate or severe renal failure has been shown by Grimlund (1963). In this investigation the development of chronic systemic acidosis, associated as it invariably was with advanced renal failure, had a particularly ominous significance. Of the seven patients who had or have subsequently developed chronic hyperchloraemic acidosis, four have died of uraemia or associated complications, one has required renal transplantation, and the remaining two show slow deterioration in renal function.

We are indebted to Dr. D. Shephard, Dr. J. Stewart, Dr. H. Pearson, and the honorary medical staff for referral of patients; to Miss Z. Barker, Miss J. Shannon, and Mr. T. Hung for technical assistance ; to Sister T. Jones for supervision of the tests; and to Mr. R. Money and Mr. J. Collins for their help.

REFERENCES

Baldwin, D. S., Gombos, E. A., and Chasis, H. (1965). American fournal of Medicine, 38,864 .

Bengtsson, U. (1962). Acta Medica Scandinavica, Suppl. No. 388.

Berlyne, G. M. (1961). Quarterly fournal of Medicine, 30, 339.

Black, D. A. K. (1965). Lancet, 2, 1141. Boyarsky, S., and Smith, H. W. (1957). Fournal of Urology, 78, 511.
Burry, A. F. (1968). Nephron, 5, 185.

Edwards, K. D. G.; Stewart, J. H., Ashley, B. C. E., and Whyte, H. M. (1964). Proceedings of the Australian Association of Clinical Bio-
chemists, 1, 101. 
Grimlund, K. (1963). Acta Medica Scandinavica, Suppl. No. 405. Gobry, A. Z., and Edwards, K. D. G. (1968). American fournal of Medicine, 45, 43.

Gyorry, A. Z., Stewart, J. H., George, C. R. P., Tiller, D. J., and Edwards, K. D. G. (1969)., Quarterly fournal of Medicine. In press. Harrow, B. R. (1967). Fournal of Urology, 97, 203.

Healy, J. K., Edwards, K. D. G., and Whyte, H. M. (1964). fournal of Clinical Pathology, 17, 557 .,

Hultengren, N. (1961). Acta Chirurgica Scandinavica, Suppl. No. 277.

Kincaid-Smith, P. (1967). Lancet, 1, 859.

Kincald-Smith, P., Saker, B. M., McKenzie, I. F. C., and Muriden, K. D. (1968). Medical fournal of Australia, 1, 203.

Kleeman, C. R., Hewitt, W. L., and Guze, L. B. (1960). Medicine (Baltimore), 39, 3.
Pearson, H. H. (1967). Medical fournal of Australia, 2, 308.

Raisz, L. G., Au, W. Y. W., and Scheer, R. L. (1959). Fournal of Clinical Investigation, 38, 8.

Reynolds, T. B., and Edmondson, H. A. (1963). Fournal of the American Medical Association, 184, 435 .

Sanerkin, N. G (1966), British fournal of Urology, 38, 361.

Spühler, O., and Zollinger, H. U. (1953). Zeitschrift für klinische Medizin, 151,1 .

Steele, T. W., Edwards, K. D. G., and Györy, A. Z. (1968). Australasian Annals of Medicine, 17, 353 .

Wrong, O., and Davies, H. E. F. (1959). Quarterly Journal of Medicine, 28, 259.

Zak, G. A.; Brun, C., and Smith, H. W. (1954). Fournal of Clinical Investigation, 33, 1064.

\title{
Clinical Trial of Emepronium Bromide in Nocturnal Frequency of Old Age
}

\author{
J. C. BROCKLEHURST,* M.D., M.R.C.P.ED., M.R.C.P.GLASG. ; J. B. DILLANE, $†$ M.B., F.R.C.S. \\ JOHN FRY, $\dagger$ M.D., F.R.C.S. ; P. ARMITAGE, $\ddagger$ PH.D.
}

British Medical fournal, 1969, 2, 216-218

\begin{abstract}
Summary : A double-blind cross-over trial of emepronium bromide (Cetiprin) in nocturnal frequency of micturition in a group of elderly women living in their homes showed that the drug was superior to placebo in diminishing urinary frequency, though not every person benefited. It is suggested that the drug may alter the established habit of rising at night to pass urine. Side-effects were negligible.
\end{abstract}

\section{Introduction}

Nocturnal frequency of micturition is one of the trials of old age. In a previous paper (Brocklehurst, Dillane, Griffiths, and Fry, 1968) we have shown it to be present in $64 \%$ of the total elderly population $(70 \%$ of males and $61 \%$ of females of 65 years and over). Its presence is not related to urinary infection and it may be assumed that this symptom often results from diminished bladder capacity associated with the characteristics of the uninhibited neurogenic bladder. We have shown (Brocklehurst and Dillane, 1966) by cystometrogram that such characteristics are often present in non-incontinent elderly women.

It is therefore reasonable to attempt to treat nocturnal frequency with drugs known to have some effect on the uninhibited neurogenic bladder. A double-blind cross-over trial of such a drug-emepronium bromide (Cetiprin)-is reported.

Emepronium bromide was synthesized in Stockholm in the early 1950s and was found to possess both a synapse-blocking action and an inhibitory effect on peripheral autonomic cholinergic nerves. Its pharmacology has been described by Hansson and Schmiterlöw (1961). Its effect on the urinary bladder was reported by Jönsson and Zederfeldt (1957). They showed by cystometrogram that emepronium bromide increased bladder capacity by an average of $20 \%$ in normal subjects and by an even greater amount in a number of participants with neurogenic bladder disorders. The effect on nocturnal frequency

\footnotetext{
- Consultant Physician in Charge of Bromley and Sidcup Geriatric Service.

+ General Practitioner, Beckenham, Kent.

$\ddagger$ Professor of Medical Statistics, London School of Hygiene and Tropical
} Medicine, London W.C.1. in old age has been studied (but not on a double-blind basis) by K. Hallen (personal communication, 1967), who showed satisfactory results in 75 to $80 \%$ of cases.

\section{Methods}

The subjects in the present trial were selected from women in one general practice whom we had found in our previous survey to have nocturnal frequency of micturition (Brocklehurst et al., 1968). They were thus selected by direct questioning and not because they were reporting symptoms of dysuria. Urinary infection was diagnosed by bacterial count of 100,000 or more per ml. Its presence did not exclude the patient from the trial. No specific treatment was given for infection during the period of the trial.

The trial lasted six weeks and was supervised by a Stateregistered nurse. It was divided into three two-week periods. During weeks 1 and 2 the participants received no treatment but recorded their habit of retiring and of rising to pass urine during the night. During weeks 3 and 4 they took tablets marked A and in weeks 5 and 6 tablets marked B. A and B were randomly allocated to the drug and an identical placebo, the allocation for any one participant remaining unknown to the participant, nurse, and physician.

Participants were instructed to take three tablets before retiring. Each active tablet contained $50 \mathrm{mg}$. of emepronium bromide, thus a nightly dose of $150 \mathrm{mg}$. was taken. The nurse visited each participant seven times, once to begin the recording, and then at weekly intervals for six further visits. On each of these visits she collected the records of the previous week and supplied the tablets for the participant to take during the next week. The nurse recorded the following data: (1) whether the participant felt that her night rest during the week was " better than," "the same as," or "worse than" the preceding week; (2) how many tablets were returned during each of weeks 3 to 6-that is, number not taken; and (3) whether the tablets had upset the participant and, if so, in what ways.

Every morning of the six-week period each participant recorded, on a special card, the number of times she had micturated during the preceding night. These cards were collected weekly by the nurse. 